the creation of the arteriovenous fistulas in the opposite limb when the patient was no longer in congestive heart failure or significantly hypertensive. This precaution has been taken to avoid significant haemodynamic effects with the arteriovenous fistula, though in clinical and radiological observation to date none of our patients has shown any evidence of cardiac decompensation.

Training for home dialysis has proceeded by using the standard Silastic-Teflon shunt for periods of up to two months and then establishing the patient in his home. After a period of one month in the home these new patients have returned to the centre to begin training for the use of their arteriovenous fistulas. It is important to stress that the mastering of the arteriovenous fistula technique for home dialysis should be delayed until the patient and family are competent at conventional home haemodialysis. After the period of training with the fistula has been completed the patient has returned home for a further month, and finally the Silastic-Teflon cannula has been electively removed.

The major danger of pumped haemodialysis is the risk of air embolus from the creation of a vacuum in the outflow line between the blood source and the blood pump. The use of a collapsible pressure monitor proximal to the blood pump has proved satisfactory in preventing the development of a vacuum in the outflow line, but in addition a monitor for detecting the blood level in the return bubble trap is being evaluated to further minimize the risk of air embolus. Additional alarms due to the extra monitors have not been troublesome, and patients have learnt to accept the occasional extra alarm as part of the inconvenience of the use of the fistula. There has been no evidence of increased red cell destruction by the continued. use of a blood pump, as indicated by an absence of a rise in free plasma haemoglobin levels after dialysis. In addition there has been a steady or rising haematocrit in all patients and zero transfusion requirements.

The most significant medical fact has been that no patient has required antibiotics since using the fistula in the home. The implication of this on the general health of the patient and the absence of recurrent infection problems remains to be more fully evaluated.
The economic impact of fistula dialysis in the home shows a slight increase in running costs due to the needles, which is more than offset by savings in the dressings required, antibiotics not used, and the cost of recurrent cannulation and declotting procedures.

\section{Conclusions}

The internal arteriovenous fistula would appear to be superior to the use of the arteriovenous shunt in home haemodialysis, eliminating many of the medical problems associated with home haemodialysis and offering patients a freer and more normal prospect of life.

We would like to thank Mr. J. S, Hanson isr the surgical creation of the arteriovenous fistulas, and Mr. P. Gowers, of Capon Heaton $\&$ Co., Ltd., for his assistance in the development of the thin-walled sac used for the outflow pressure monitor.

\section{REFERENCES}

Ackman, C. F. D., Khonsari, H., Mount, B., Rege, P., and Dossetor, J. B. (1968). Proc. Europ. Dial. Transpl.' Ass., 4, 86

Bienenstock, J., and Shaldon, S. (1963). Lancet, 2, 815.

Brescia, M. J., Cimino, J. E., Appel, K., and Hurwich, B. J. (1966). New Engl. ₹. Med., 275, 1089

Cohen, S., Lidsky, I., Kest, L., Kastagir, B., and Vertes, V. (1968). Trans. Amer. Soc. artif. intern. Organs, $14,421$.

Curtis, F. K., Cole, J. J., Fellows, B. J., Tyler, L. L., and Scribner, B. H. (1965). Trans. Amer. Soc. artif. intern. Organs, 11, 7.

Drukker, W., Jungerius, N. A., and Alberts, C. (1968). Proc. Europ. Dial. Transpl. Ass., 4, 3.

Hanson, J. S., Carmody, M., Keogh B., and O'Dwyer, W. F. (1967). Brit. med. F., 4, 586.

Hilton, D. D., Blainey, J. D., Dawson-Edwards, P., Dorricott, N. J., and Simpson, K. M. (1968). Proc. Europ. Dial. Transpl. Ass., 4, 35. Patel, R., Lidsky, I., Vertes, V., Kest, L., and Cohen, S. (1968). Brit. med. F., 1,414

Rae, A. I., Barnett, B. M. S., Davidson, R. C., and Blagg, C. R. (1968). Proc. Europ. Dial. Transpl. Ass., 4, 28.

Shaldon, S., Baillod, R., Comty, C., Oakley, J., and Sevitt, L. (1964). Dialysis, p. 66. Seattle.

Shaldon, S., Chiandussi, L., and Higgs, B. (1961). Lancet, 2, 857.

Shaldon, S., Baillod, R., Comty, C., Oakley J., and Sevit, L. (1964). Proc. Europ. Dial. Transpl. Ass., 1, 233.

Shaldon, S., and Oakley, J. J. (1968). Proc. Europ. Dial. Transpl. Ass., 4,24 .

Shaldon S., Ramalingum, C., and Baillod, R. A. (1966). Proc. Europ. Dial. Transpl. Ass., 2, 280.

Verberckmoes, R., et al. (1968). Proc. Europ. Dial. Transpl. Ass., 4, 73.

\title{
Value and Limitations of Electrocardiogram in Diagnosis of Slight and Subacute Coronary Attacks
}

\author{
DAVID SHORT,* M.D., PH.D., F.R.C.P.
}

Summary : The electrocardiogram recorded at the initial $\checkmark$ consultation was compared with the final diagnosis in 211 consecutive suspected slight or sub-acute coronary attacks in 206 patients.

In $77(36 \%)$ of the 211 episodes, acute (or subacute) myocardial infarction was finally diagnosed. The initial E.C.G. showed a diagnostic pattern in only $19(25 \%)$ of these 77 episodes; in $39(50 \%)$ it was abnormal but not diagnostic of recent infarction; while in $19(25 \%)$ the E.C.G. showed no abnormality classified under the Minnesota Code, though in $\mathbf{1 6}$ of these there were definite minor changes.

In $61(29 \%)$ of the 211 episodes acute myocardial infarction was excluded and an alternative diagnosis was made. The E.C.G. was strictly normal in only 23 (38\%) of these 61 episodes; in $15(25 \%)$ it showed minor abnormalities, and in $23(38 \%)$ it was grossly abnormal.

\section{Introduction}

The value of the electrocardiogram (E.C.G.) in the diagnosis of major attacks of myocardial infarction is well established, but it is too readily assumed that the E.C.G. affords a simple and decisive means of diagnosis in the case of slight and subacute attacks. Because of this there is a growing demand that hospitals should make arrangements for carrying out E.C.G. examinations of patients at the request of their family doctors, and report on the tracings without the cardiologist seeing the patient. It is clearly desirable that the family physician should be furnished with every means for increasing his diagnostic accuracy, but it seems to me that the value and limitations of the E.C.G. in the diagnosis of suspected coronary attacks need to be clearly defined. The following study was undertaken with this object. In essence it is a correlation between the E.C.G. pattern recorded

\footnotetext{
* Consultant Physician. Aberdeen Royal Infirmary.
} 
at the initial consultation on patients with suspected coronary attacks and the final diagnosis.

\section{Material and Methods}

In a two-year prospective study 206 patients were seen in consultation at the request of the family physician on account of a suspected coronary attack. Five patients were seen in two attacks. In none was the patient shocked or regarded by the doctor as ill enough to warrant urgent hospital admission. In the majority the consultation was undertaken within 48 hours, and in only a very few was an immediate visit requested ; $80 \%$ were seen in their homes, and the remainder were regarded as fit enough for an appointment at the outpatient clinic or privaie consulting-room. Four domiciliary consultations during this period were excluded from the series because in these the family doctor had made a confident and correct diagnosis of myocardial infarction and advised admission to hospital; but the patient had not accepted this advice.

Of the 211 episodes 114 (54\%) were in males. In $20 \%$ the patients were under 50 years of age, in $53 \%$ between 50 and 69 , and in $27 \% 70$ and over. In $50(24 \%)$ there was a history of previous proved myocardial infarction.

Each patient was questioned about symptoms and previous history. The family history was also sought provided this could be elicited without increasing his or her anxiety. In addition, patients were questioned about any drugs they were taking, and were asked to produce the bottles for inspection. In this way it was possible to ascertain whether they were taking one of the cardiac glycosides. The cardiovascular system was then examined, and other systems as seemed relevant.

The E.C.G. was recorded on a direct-writing Cambridge Transrite Mark II or III machine at a paper speed of $25 \mathrm{~mm}$./ sec. Twelve leads were recorded routinely: the three standard bipolar leads, the three unipolar leads, and six precordial V leads. Leads III and aVF were re-recorded in full inspiration in cases where there was a doubtful $\mathrm{Q}, \mathrm{S}-\mathrm{T}$, or $\mathrm{T}$-wave abnormality in these leads. In cases where the diagnosis was already obvious leads V3 and V5 were sometimes omitted. Occasionally a second set of precordial leads was recorded at a higher level. An effort test was never performed because of its danger in patients with recent myocardial infarction. An aspartate transaminase (S.G.O.T.) and alanine transaminase (S.G.P.T.) estimation was done in cases seen within 72 hours of the onset if the clinical and E.C.G. evidence was inconclusive.

A working diagnosis was made at the time of consultation on the evidence available (including in some cases previous E.C.G.s), and this formed the basis of the immediate management. The majority of those diagnosed confidently as having acute or subacute myocardial infarction were admitted to hospital, as also were many of those in whom this diagnosis seemed probable. All cases in these two categories, as well as those regarded as doubtful, had further E.C.G.s, and, when appropriate, repeated serum enzyme estimations. In the event of death a necropsy was requested and special attention was directed to the state of the heart. At the conclusion of the illness the evidence was reviewed and a final diagnosis made.

\section{Final Diagnosis}

Acute myocardial infarction was the final diagnosis in 77 of the 211 episodes. The diagnosis was based on post-mortem evidence of recent infarction in three patients, an E.C.G. showing localized S-T elevation in 23 patients, localized $T$-wave abnormality with classical evolution in 35 patients, and a diagnostic serum enzyme pattern (in association with clinical evidence) in 16 patients. The outcome of the disease in these 77 episodes was death in 6 , major extension (non-fatal) in 4 , and uncomplicated resolution in 67 .
Probable acute myocardial infarction was the final diagnosis in 36 episodes. Such a diagnosis was made if a patient with typical anginal pain on effort developed a prolonged attack of similar pain at rest, with a fixed E.C.G. abnormality, and without significant rise of serum enzymes. Many of these patients probably had small infarcts; others may have developed thrombosis without infarction.

Possible acute myocardial infarction was the final diagnosis in 37 episodes. Such a diagnosis was made in patients with chest pain which was not typical of angina but who had abnormal E.C.G.s consistent with coronary heart disease. Some of these probably had a virus myocarditis.

Acute myocardial infarction was excluded and an alternative diagnosis established in 61 episodes. The alternative diagnosis was a cardiac condition in 22, and non-cardiac in 39 (Table I). Among the cardiac conditions simulating myocardial infarction the commonest was an arrhythmia producing discomfort in the chest, particularly if this was associated with heart failure giving rise to dyspnoea and perhaps hepatic pain. The second commonest coronary mimic was a prolonged attack of cardiac pain at rest due to anxiety in a patient with chronic coronary disease. The commonest non-cardiac conditions were pulmonary and neuromuscular.

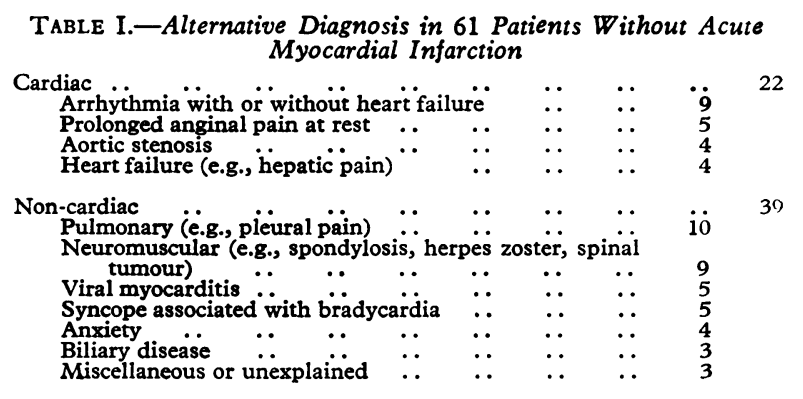

\section{Analysis of the Electrocardiogram}

The E.C.G.s were analysed primarily on the basis of the Minnesota code (Blackburn et al., 1960). Tracings showing no codifiable abnormality were further subdivided into those showing the lesser signs of restricted myocardial infarction described by Evans (1965) and those showing no recognizable abnormality. The E.C.G. patterns fell into seven groups as follows:

I. Classical appearances of recent myocardial infarction, including S-T segment elevation.

II. Abnormal $Q$ waves in association with gross depression of the $S-T$ segment and/or flattening or inversion of $T$ waves.

III. Gross depression of the S-T segment and/or flattening or inversion of $T$ waves without abnormal $Q$ waves.

IV. A pattern entirely consistent with left ventricular hypertrophy. V. Miscellaneous abnormalities such as bundle-branch block.

VI. Minor depression of the S-T segment and/or $T$ wave, not abnormal by the Minnesota code.

VII. No abnormality.

\section{Initial Electrocardiogram and Final Diagnosis}

The correlation between the initial E.C.G. and the final diagnosis is shown in Table II.

Initial Electrocardiogram in Acute (or Subacute) Myocardial Infarction.-In 19 of the 77 episodes of acute myocardial infarction the initial E.C.G. showed S-T elevation (group I). (Four more patients developed this pattern later.) In nine episodes (group II) there was conclusive evidence and in 23 (group III) there was suggestive evidence of myocardial infarction without any indication whether this was acute or not. In seven the changes were simply those of left ventricular hypertrophy (group IV), and in 19 the E.C.G. showed no abnormality 
classifiable under the Minnesota code (groups VI and VII). Ten of the 19 E.C.G.s showing no codifiable abnormality exhibited one or more of the lesser signs described by Evans (1965), and a further six were found to be abnormal when compared with previous or subsequent E.C.G.s. The com-

\begin{tabular}{|c|c|c|c|c|c|c|}
\hline \multirow{2}{*}{ E.C.G. Pattern } & \multicolumn{2}{|c|}{ Episodes } & \multicolumn{4}{|c|}{$\begin{array}{l}\text { Final Diagnosis of Acute } \\
\text { Myocardial Infarction }\end{array}$} \\
\hline & Total & $\begin{array}{l}\text { Previous } \\
\text { Infarct }\end{array}$ & Definite & $\begin{array}{c}\text { Prob- } \\
\text { able }\end{array}$ & $\begin{array}{l}\text { Pos- } \\
\text { sible }\end{array}$ & $\begin{array}{l}\text { Ex- } \\
\text { cluded }\end{array}$ \\
\hline 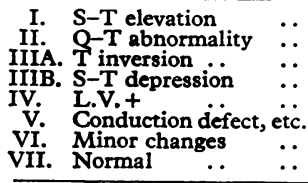 & $\begin{array}{l}19 \\
16 \\
38 \\
17 \\
27 \\
11 \\
41 \\
42\end{array}$ & $\begin{array}{r}3 \\
9 \\
14 \\
2 \\
10 \\
0 \\
9 \\
3\end{array}$ & $\begin{array}{r}19 \\
9 \\
17 \\
6 \\
7 \\
0 \\
10 \\
9\end{array}$ & $\begin{array}{l}0 \\
1 \\
8 \\
7 \\
3 \\
3 \\
9 \\
5\end{array}$ & $\begin{array}{l}0 \\
3 \\
7 \\
1 \\
9 \\
5 \\
7 \\
5\end{array}$ & $\begin{array}{r}0 \\
3 \\
6 \\
3 \\
8 \\
3 \\
15 \\
23\end{array}$ \\
\hline & 211 & 50 & 77 & 36 & 37 & 61 \\
\hline
\end{tabular}

TABLE III.-Cause of Abnormal Electrocardiogram in Patients Without Acute Myocardial Infarction

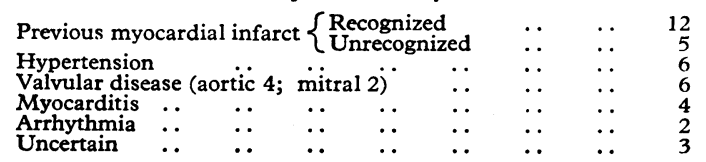

monest abnormalities were low $\mathrm{T}$ waves and slight $\mathrm{S}-\mathrm{T}$ depression, and these abnormalities were commonly combined. Three cases showed minor S-T elevation. Ten of these 19 patients subsequently developed major E.C.G. abnormalities, and one died. Nine showed no progression of the E.C.G. changes, but four of these had a significant enzyme rise.
Initial Electrocardiogram in Episodes in which Acute Myocardial Infarction was Excluded.-The E.C.G. was abnormal in 38 of the 61 episodes in which an alternative diagnosis was made. In 23 episodes it was grossly abnormal, in 15 it showed minor changes, and it was strictly normal in only 23. The causes of the E.C.G. abnormalities are shown in Table III.

\section{Conclusions}

The value of the E.C.G. in the diagnosis of suspected coronary attacks lies in the fact that a single tracing is virtually diagnostic in a proportion of cases (about $25 \%$ in this series), and serial tracings are the most useful method of confirming the diagnosis in the remainder.

The limitation of the E.C.G. lies in the fact that a single tracing recorded early in an attack of myocardial infarction frequently shows no absolutely diagnostic features, whereas in attacks not due to myocardial infarction the E.C.G. is of ten grossly abnormal on account of previous infarction or other cardiac disease.

An accurate early diagnosis of suspected coronary attacks depends on a critical evaluation of history, clinical findings, and E.C.G. The only satisfactory way of achieving this is for the doctor who reports on the E.C.G. to examine the patient himself.

\section{REFERENCES}

Blackburn, H., Keys, A., Simonson, E., Rautaharju, P., and Punsar, S. (1960). Circulation, 21, 1160

Evans, W. (1965). Brit. Heart f., 27, 856.
The continued high mortality rate of patients admitted to hospital with myocardial infarction (Honey and Truelove, 1957) has led to the introduction of coronary care units (Lawrie et al., 1967 ; Restieaux et al., 1967 ; Pentecost and Mayne, 1968 ; Thomas et al., 1968) and more recently to flying squad services (Pantridge and Geddes, 1967). Few reports have been

* General Practitioner, Southampton. published dealing with the prognosis of patients treated at home (Fry and Dillane, 1967).

This paper records the results of home treatment of patients suffering from myocardial infarction in one general practice over a four-year period.

\section{Patients}

During the four years from 1 June 1964 to 31 May 1968 50 patients were seen in one general practice in whom the diagnosis of myocardial infarction was made. Twenty-six survived the immediate period of infarction and form the main basis of this paper. The remaining 24 were dead on discovery by their relatives or dead on arrival of the family doctor. None of this latter group was suitable for resuscitation owing to the time lapse.

Nineteen of the surviving 26 patients were men aged 41 to 75 years, and seven were women aged 51 to 78 years. Eleven patients were in social class III and the remainder were evenly distributed through the other four classes. Fourteen patients had coexisting diseases (Table I).

\section{Criteria for Diagnosis}

Patients Found Dead.-In all 24 patients found dead there was a history of angina pectoris, and all had been diagnosed 